\title{
Discovery of $\mathrm{CH}_{2} \mathrm{CHCCH}$ and detection of $\mathrm{HCCN}, \mathrm{HC}_{4} \mathrm{~N}$, $\mathrm{CH}_{3} \mathrm{CH}_{2} \mathrm{CN}$, and, tentatively, $\mathrm{CH}_{3} \mathrm{CH}_{2} \mathrm{CCH}$ in TMC-1 ${ }^{\star}$
}

\author{
J. Cernicharo' ${ }^{1}$, M. Agúndez ${ }^{1}$, C. Cabezas ${ }^{1}$, N. Marcelino ${ }^{1}$, B. Tercero ${ }^{2,3}$, J. R. Pardo ${ }^{1}$, J. D. Gallego ${ }^{2}$, F. Tercero ${ }^{2}$, \\ J. A. López-Pérez ${ }^{2}$, and P. de Vicente ${ }^{2}$ \\ ${ }^{1}$ Grupo de Astrofísica Molecular, Instituto de Física Fundamental (IFF-CSIC), C/ Serrano 121, 28006 Madrid, Spain \\ e-mail: jose. cernicharo@csic.es \\ 2 Centro de Desarrollos Tecnológicos, Observatorio de Yebes (IGN), 19141 Yebes, Guadalajara, Spain \\ 3 Observatorio Astronómico Nacional (IGN), C/ Alfonso XII, 3, 28014 Madrid, Spain
}

Received 28 January 2021 / Accepted 15 February 2021

\begin{abstract}
We present the discovery in TMC-1 of vinyl acetylene, $\mathrm{CH}_{2} \mathrm{CHCCH}$, and the detection, for the first time in a cold dark cloud, of $\mathrm{HCCN}, \mathrm{HC}_{4} \mathrm{~N}$, and $\mathrm{CH}_{3} \mathrm{CH}_{2} \mathrm{CN}$. A tentative detection of $\mathrm{CH}_{3} \mathrm{CH}_{2} \mathrm{CCH}$ is also reported. The column density of vinyl acetylene is $(1.2 \pm 0.2) \times 10^{13} \mathrm{~cm}^{-2}$, which makes it one of the most abundant closed-shell hydrocarbons detected in TMC-1. Its abundance is only three times lower than that of propylene, $\mathrm{CH}_{3} \mathrm{CHCH}_{2}$. The column densities derived for $\mathrm{HCCN}$ and $\mathrm{HC}_{4} \mathrm{~N}$ are $(4.4 \pm 04) \times 10^{11} \mathrm{~cm}^{-2}$ and $(3.7 \pm 0.4) \times 10^{11} \mathrm{~cm}^{-2}$, respectively. Hence, the $\mathrm{HCCN} / \mathrm{HC}_{4} \mathrm{~N}$ abundance ratio is $1.2 \pm 0.3$. For ethyl cyanide we derive a column density of $(1.1 \pm 0.3) \times 10^{11} \mathrm{~cm}^{-2}$. These results are compared with a state-of-the-art chemical model of TMC-1, which is able to account for the observed abundances of these molecules through gas-phase chemical routes.
\end{abstract}

Key words. molecular data - line: identification - ISM: molecules - ISM: individual objects: TMC-1 - astrochemistry

\section{Introduction}

The chemical complexity of the interstellar medium has been demonstrated by the detection of more than 200 different chemical species. In this context, the cold dark core TMC-1 presents an interesting carbon-rich chemistry that led to the formation of long neutral carbon-chain radicals and their anions (see Cernicharo et al. 2020a, and references therein). Cyanopolyynes, which are stable molecules, are also particularly abundant in TMC-1 (see Cernicharo et al. 2020b,c, and references therein). The chemistry of this peculiar object produces a large abundance of the nearly saturated species $\mathrm{CH}_{3} \mathrm{CHCH}_{2}$, which could mostly be a typical molecule of hot cores (Marcelino et al. 2007). The polar benzenic ring $\mathrm{C}_{6} \mathrm{H}_{5} \mathrm{CN}$ has also been detected for the first time in space in this object (McGuire et al. 2018), while benzene itself has only so far been been detected toward post-asymptotic giant branch objects (Cernicharo et al. 2001).

Sensitive line surveys are the best tools for unveiling the molecular content of astronomical sources and searching for new molecules. A key element for carrying out a detailed analysis of line surveys is the availability of exhaustive spectroscopic information of the already-known species, their isotopologues, and their vibrationally excited states. The ability to identify the maximum possible number of spectral features leaves the cleanest possible forest of unidentified ones, therefore opening up a chance to discover new molecules and get insights into the

* Based on observations carried out with the Yebes $40 \mathrm{~m}$ telescope (projects 19A003, 19A010, 20A014, 20D023). The $40 \mathrm{~m}$ radio telescope at Yebes Observatory is operated by the Spanish Geographic Institute (IGN, Ministerio de Transportes, Movilidad y Agenda Urbana). chemistry and chemical evolution of the observed objects. In this context we have recently succeeded in discovering, prior to any spectroscopic information from the laboratory, several new molecular species (see, e.g., Cernicharo et al. 2020a,b,c, 2021a,b; Marcelino et al. 2020). Consequently, the astronomical object under study has become a real spectroscopic laboratory. Experience shows that, if the sensitivity of a line survey is sufficiently high, many unknown species will be discovered, providing key information on the ongoing chemical processes in the cloud.

In this Letter we report on the discovery of vinyl acetylene, $\mathrm{CH}_{2} \mathrm{CHCCH}$, a species that has been spectroscopically characterized but never detected in space. We also present the detection, for the first time in a cold dark cloud, of $\mathrm{HCCN}, \mathrm{HC}_{4} \mathrm{~N}$, and $\mathrm{CH}_{3} \mathrm{CH}_{2} \mathrm{CN}$. Ethyl acetylene, $\mathrm{CH}_{3} \mathrm{CH}_{2} \mathrm{CCH}$, has also been tentatively detected.

\section{Observations}

New receivers, built within the Nanocosmos project ${ }^{1}$ and installed at the Yebes $40 \mathrm{~m}$ radio telescope, were used for the observations of TMC- 1 . The $Q$-band receiver consists of two high electron mobility transistor cold amplifiers covering the 31.0-50.3 GHz range with horizontal and vertical polarizations. Receiver temperatures vary from $17 \mathrm{~K}$ at $32 \mathrm{GHz}$ to $25 \mathrm{~K}$ at $50 \mathrm{GHz}$. Eight $2.5 \mathrm{GHz}$ wide fast Fourier transform spectrometers, with a spectral resolution of $38.15 \mathrm{kHz}$, provide the whole

\footnotetext{
1 https://nanocosmos.iff.csic.es/
} 
coverage of the $Q$-band in each polarization. The main beam efficiency varies from 0.6 at $32 \mathrm{GHz}$ to 0.47 at $50 \mathrm{GHz}$. A detailed description of the system is given in Tercero et al. (2021).

The line survey of TMC- $1\left(\alpha_{J 2000}=4^{\mathrm{h}} 41^{\mathrm{m}} 41 \mathrm{~s} .9\right.$ and $\delta_{J 2000}=$ $+25^{\circ} 41^{\prime} 27^{\prime \prime}(0)$ in the $Q$-band was performed over several sessions. Previous results obtained from the line survey were based on two observing runs, one performed in November 2019 and one in February 2020. They concerned the detection of $\mathrm{C}_{3} \mathrm{~N}^{-}$and $\mathrm{C}_{5} \mathrm{~N}^{-}$(Cernicharo et al. 2020b), $\mathrm{HC}_{5} \mathrm{NH}^{+}$(Marcelino et al. 2020), $\mathrm{HC}_{4} \mathrm{NC}$ (Cernicharo et al. 2020c), and $\mathrm{HC}_{3} \mathrm{O}^{+}$ (Cernicharo et al. 2020a). Additional data were taken in October 2020, December 2020, and January 2021 to improve the line survey and to further check the consistency of all observed spectral features. These new data allowed the detection of $\mathrm{HC}_{3} \mathrm{~S}^{+}$(Cernicharo et al. 2021a) along with the acetyl cation, $\mathrm{CH}_{3} \mathrm{CO}^{+}$(Cernicharo et al. 2021b), the isomers of $\mathrm{C}_{4} \mathrm{H}_{3} \mathrm{~N}$ (Marcelino et al. 2021), and HDCCN (Cabezas et al. 2021).

Two different frequency coverages were used in the line survey, $31.08-49.52 \mathrm{GHz}$ and $31.98-50.42 \mathrm{GHz}$, to ensure that no spurious spectral ghosts were produced in the down-conversion chain, which down-converts the signal from the receiver to $1-19.5 \mathrm{GHz}$ and then splits it into eight $2.5 \mathrm{GHz}$ bands, which are finally analyzed by the FFTs. The observing procedure was frequency switching with a frequency throw of $10 \mathrm{MHz}$ for the first two runs and $8 \mathrm{MHz}$ for the later ones. The intensity scale (i.e., the antenna temperature, $T_{\mathrm{A}}^{*}$ ) was calibrated using two absorbers at different temperatures and the atmospheric transmission model (ATM; Cernicharo 1985; Pardo et al. 2001). Calibration uncertainties were adopted to be $10 \%$. The nominal spectral resolution of $38.15 \mathrm{kHz}$ was kept for the final spectra. The sensitivity varied across the $Q$-band from 0.5 to $2.0 \mathrm{mK}$. All data were analyzed using the GILDAS package ${ }^{2}$.

\section{Results and discussion}

The sensitivity of our observations toward TMC-1 (see Sect. 2) is a factor of 10-20 better than previously published line surveys of this source at the same frequencies (Kaifu et al. 2004). This large improvement allowed us to detect a forest of weak lines, most of which arise from the isotopologues of abundant species such as $\mathrm{HC}_{3} \mathrm{~N}, \mathrm{HC}_{5} \mathrm{~N}$, and $\mathrm{HC}_{7} \mathrm{~N}$ (Cernicharo et al. 2020c). In fact, it was possible to detect many individual lines (Marcelino et al. 2021) from molecular species that had previously only been reported using stacking techniques. Taking into account, on one hand, the large abundances found in TMC-1 for cyanide derivatives of abundant species and, on the other, the presence of nearly saturated hydrocarbons such as $\mathrm{CH}_{3} \mathrm{CHCH}_{2}$ (Marcelino et al. 2007), we searched for species such as $\mathrm{CH}_{2} \mathrm{CHCCH}$ and $\mathrm{CH}_{3} \mathrm{CH}_{2} \mathrm{CCH}$, as well as for cyanides found previously only in carbon-rich stars $\left(\mathrm{HCCN}\right.$ and $\left.\mathrm{HC}_{4} \mathrm{~N}\right)$ or in warm molecular clouds $\left(\mathrm{CH}_{3} \mathrm{CH}_{2} \mathrm{CN}\right)$. Line identifications in this TMC-1 survey were performed using the MADEX catalogue (Cernicharo 2012), the Cologne Database of Molecular Spectroscopy (CDMS) catalogue (Müller et al. 2005), and the JPL catalogue (Pickett et al. 1998).

\subsection{Vinyl acetylene, $\mathrm{CH}_{2} \mathrm{CHCCH}$}

Spectroscopic constants for $\mathrm{CH}_{2} \mathrm{CHCCH}$ were derived from a fit to the lines reported by Thorwirth et al. (2004) and implemented in the MADEX code (Cernicharo 2012). We detected six lines with $K_{a}=0$ and 1 (see Fig. 1). Although the observed line

\footnotetext{
2 http://wWw.iram.fr/IRAMFR/GILDAS
}

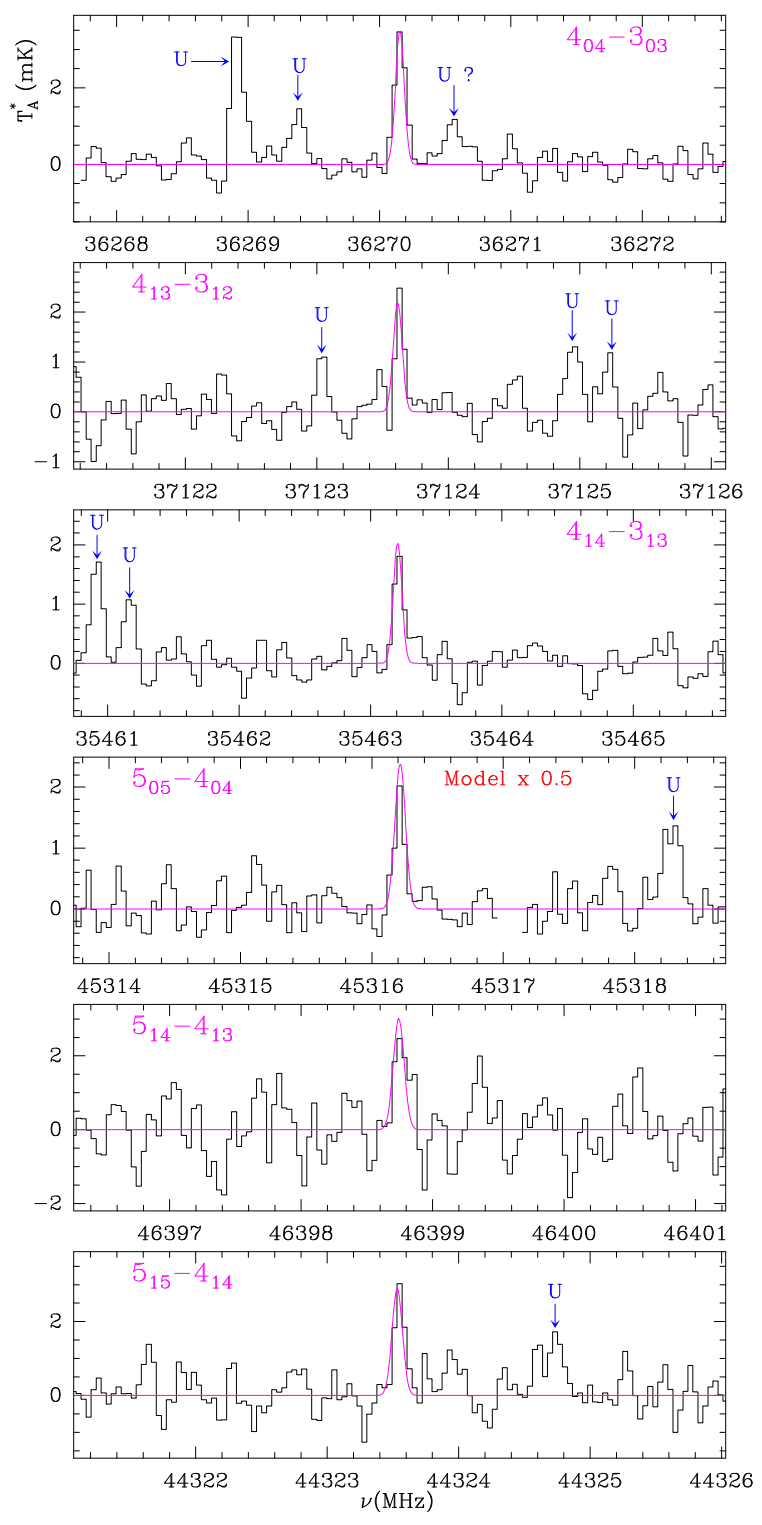

Fig. 1. Observed transitions of $\mathrm{CH}_{2} \mathrm{CHCCH}$ toward TMC-1. The abscissa corresponds to the rest frequency of the lines assuming a $v_{\mathrm{LSR}}$ for the source of $5.83 \mathrm{~km} \mathrm{~s}^{-1}$. Frequencies and intensities for the observed lines are given in Table A.1. The ordinate is the antenna temperature, corrected for atmospheric and telescope losses, in millikelvins (mK). The purple line shows the synthetic spectrum obtained for this species.

intensities (see Table A.1) are low $(\sim 2-3 \mathrm{mK})$, the column density for this molecule should be particularly large as its dipole moment, $\mu_{a}$, is only $0.43 \mathrm{D}$ (Sobolev et al. 1962; Thorwirth \& Lichau 2003). Only a $K_{a}=2$ line was marginally detected, corresponding to the $4_{22}-3_{21}$ rotational transition. Assuming a uniform source with a radius of 40" (Fossé et al. 2001) and through a standard rotational diagram, we derived a rotational temperature of $5.0 \pm 0.5 \mathrm{~K}$ and a column density for vinyl acetylene of $(1.2 \pm 0.2) \times 10^{13} \mathrm{~cm}^{-2}$. Figure 1 shows the synthetic spectrum of $\mathrm{CH}_{2} \mathrm{CHCCH}$ computed for the derived rotational temperature and column density (see Appendix A). The comparison with the data shows a very good agreement for all lines, with the exception of the $5_{05}-4_{04}$ transition, for which the predicted intensity is nearly a factor of two larger than what is observed. This line is probably affected by a negative spectral feature resulting from the folding of the frequency switching data. 


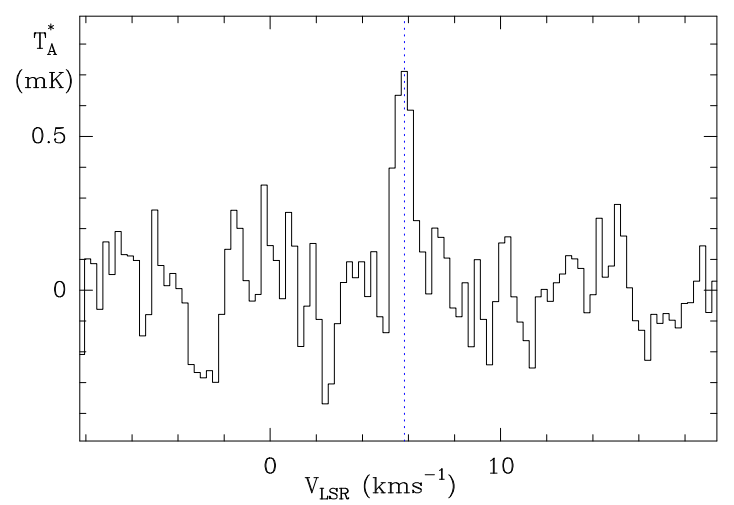

Fig. 2. Line profile for $\mathrm{CH}_{3} \mathrm{CH}_{2} \mathrm{CCH}$ toward TMC-1 from stacking the signal from the transitions of this species in the $31-50 \mathrm{GHz}$ frequency range. The abscissa corresponds to the local standard of rest velocity. The ordinate is the antenna temperature, corrected for atmospheric and telescope losses, in $\mathrm{mK}$. The observed spectra from the individual lines are shown in Fig. B.1.

Using the column density of $\mathrm{H}_{2}$ derived by Cernicharo \& Guélin (1987), the abundance of $\mathrm{CH}_{2} \mathrm{CHCCH}$ relative to $\mathrm{H}_{2}$ toward TMC- 1 is $1.2 \times 10^{-9}$. This abundance is only three times lower than that of propylene (Marcelino et al. 2007), and ten times lower than that of methyl acetylene (Cabezas et al. 2021). Hence, vinyl acetylene is one of the most abundant hydrocarbons in TMC-1 and probably the most abundant compound containing four carbon atoms. It is interesting to compare the abundance of vinyl acetylene with that of vinyl cyanide. We analyzed the lines of $\mathrm{CH}_{2} \mathrm{CHCN}$ covered by our $Q$-band data. We derived a rotational temperature of $4.5 \pm 0.3 \mathrm{~K}$, and $N\left(\mathrm{CH}_{2} \mathrm{CHCN}\right)=(6.5 \pm 0.5) \times 10^{12} \mathrm{~cm}^{-2}$ (see Appendix C). Hence, the abundance ratio between the acetylenic and cyanide derivatives of ethylene $\left(\mathrm{CH}_{2} \mathrm{CH}_{2}\right)$ is $1.8 \pm 0.4$, which suggests that ethylene could be a likely precursor of $\mathrm{CH}_{2} \mathrm{CHCCH}$ and $\mathrm{CH}_{2} \mathrm{CHCN}$ through reactions with $\mathrm{CCH}$ and $\mathrm{CN}$, respectively (see Sect. 3.4 for more details).

We searched for $\mathrm{CH}_{3} \mathrm{CH}_{2} \mathrm{CCH}$ in our survey. Figure 2 shows the resulting spectrum from stacking the lines of this species covered in our data (see details in Appendix B). The whole set of individual lines is shown in Fig. B.1. We consider this molecule to be tentatively detected with a column density of $9 \times 10^{11} \mathrm{~cm}^{-2}$. We also detected ethyl cyanide, $\mathrm{CH}_{3} \mathrm{CH}_{2} \mathrm{CN}$, in TMC-1 (see Sect. 3.3) with a column density of $10^{11} \mathrm{~cm}^{-2}$. Hence, assuming that $\mathrm{CH}_{3} \mathrm{CH}_{2} \mathrm{CCH}$ in TMC-1 is detected, the abundance ratio $\mathrm{CH}_{3} \mathrm{CH}_{2} \mathrm{CCH} / \mathrm{CH}_{3} \mathrm{CH}_{2} \mathrm{CN}$ is $\sim 9$.

\section{2. $\mathrm{HCCN}$ and $\mathrm{HC}_{4} \mathrm{~N}$}

The cyano methylene radical, HCCN, was detected toward the carbon-rich star IRC +10216 by Guélin \& Cernicharo (1991). The molecule has been observed in the laboratory by several authors (Saito et al. 1984; Endo \& Ohshima 1993; McCarthy et al. 1995; Allen et al. 2001). Its dipole moment is $3.04 \mathrm{D}$ (Inostroza et al. 2012). Given the large abundance of cyanopolyynes in TMC-1 (e.g., Cernicharo et al. 2020c), HCCN could be expected in this source, although it was searched for by McGonagle \& Irivine (1996) with no success. Several of its rotational transitions, which show significant hyperfine splitting, are within the frequency range of our TMC-1 survey. All of them were detected, as shown in Fig. 3 (see Table A.1). This is the first time HCCN has been detected in cold interstellar clouds. The range of level energies covered by the observed transitions,

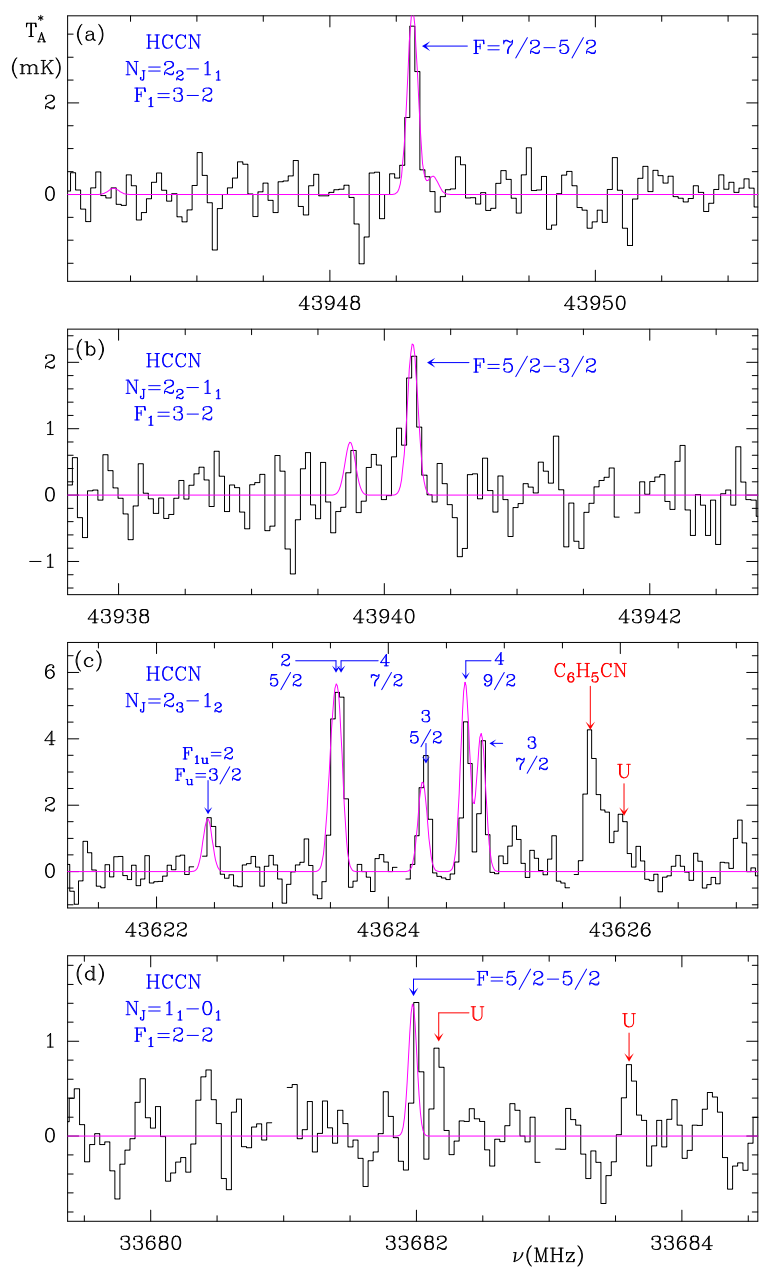

Fig. 3. Observed lines of HCCN in our $Q$-band survey toward TMC1. The abscissa corresponds to the rest frequency assuming a $v_{\mathrm{LSR}}$ of the source of $5.83 \mathrm{~km} \mathrm{~s}^{-1}$. The ordinate is the antenna temperature, corrected for atmospheric and telescope losses, in $\mathrm{mK}$. The violet line shows the synthetic spectrum computed for $T_{\mathrm{r}}=4.5 \mathrm{~K}$ and $\mathrm{N}(\mathrm{HCCN})=4.4 \times 10^{11} \mathrm{~cm}^{-2}$. For the sake of clarity, only the upper quantum numbers $F_{1}$ and $F$ are provided in panel $c$.

1.6-3.7 K, did not allow us to build a reliable rotational diagram. We adopted the rotational temperature derived for $\mathrm{CH}_{2} \mathrm{CHCN}$ $(4.5 \pm 0.5 \mathrm{~K}$; see Sect. 3.1$)$ and computed a synthetic spectrum with the column density as a free parameter. The best fit was obtained for a column density of $(4.4 \pm 0.4) \times 10^{11} \mathrm{~cm}^{-2}$. As shown in Fig. 3, the match between the model and the observations is very good.

In addition to $\mathrm{HCCN}$, the linear cyano ethynyl-methylene radical, $\mathrm{HC}_{4} \mathrm{~N}$, was also detected in $\mathrm{IRC}+10216$ (Cernicharo et al. 2004). Spectroscopic information on this molecule (Tang et al. 1999) was implemented in MADEX. Its dipole moment is 4.33 D (Ikuta et al. 2000). The observed lines toward TMC-1 are shown in Fig. 4. From those lines and the model fitting procedure, it is possible to derive a rotational temperature of $4 \pm 1 \mathrm{~K}$ and a column density of $(3.7 \pm 0.4) \times 10^{11} \mathrm{~cm}^{-2}$. Figure 4 shows the synthetic spectrum corresponding to these parameters. The agreement with the observations is very good. This is the first time that this species has been detected in a cold dark cloud.

We searched for the bent and cyclic isomers of $\mathrm{HC}_{4} \mathrm{~N}$ (McCarthy et al. 1999a,b) without success. We derived $3 \sigma$ upper limits to their column densities of $1.5 \times 10^{11} \mathrm{~cm}^{-2}$ and $1.0 \times 10^{11} \mathrm{~cm}^{-2}$, respectively. It is interesting to note that these 

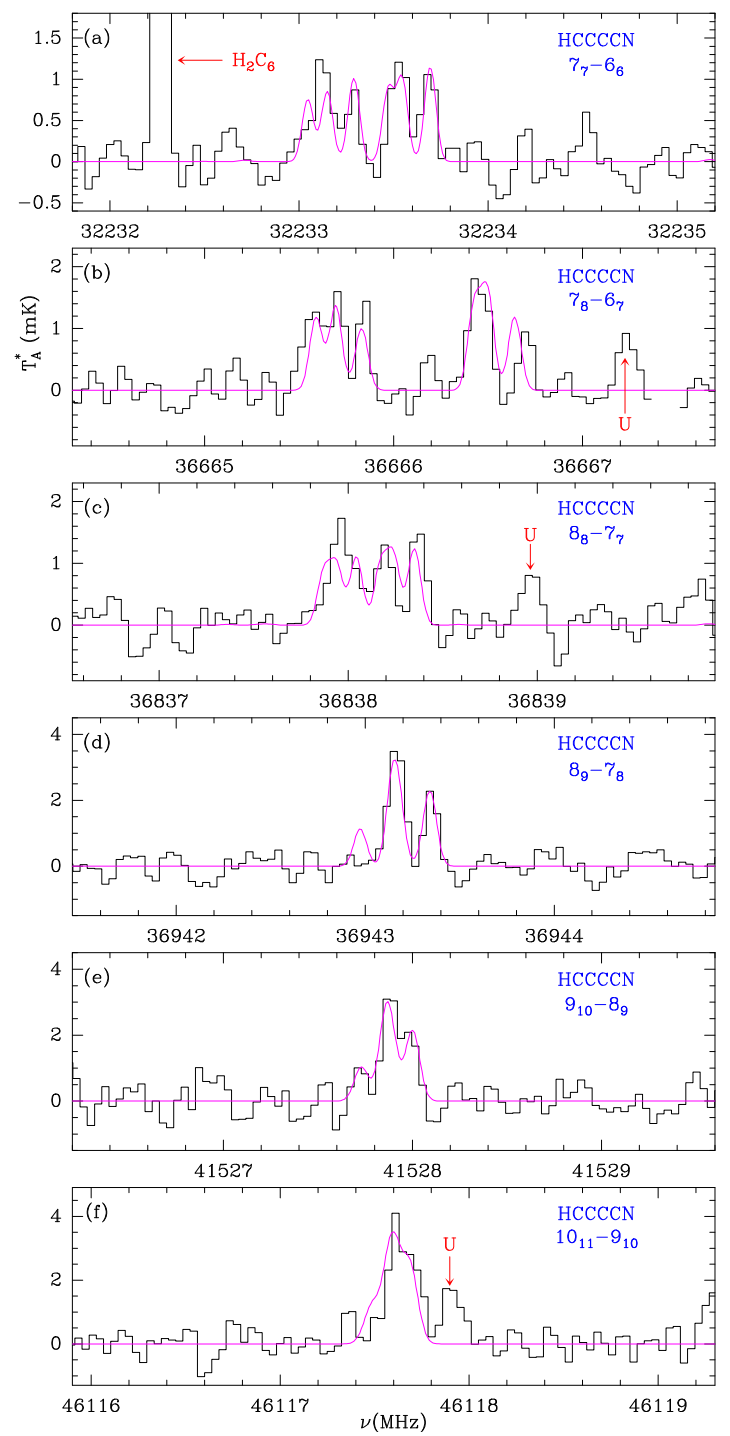

Fig. 4. Selected lines of $\mathrm{HC}_{4} \mathrm{~N}$ in the $31-50 \mathrm{GHz}$ frequency range toward TMC-1. The abscissa corresponds to the rest frequency assuming a $v_{\mathrm{LSR}}$ for TMC-1 of $5.83 \mathrm{~km} \mathrm{~s}^{-1}$. The ordinate is the antenna temperature, corrected for atmospheric and telescope losses, in $\mathrm{mK}$. The violet line shows the synthetic spectrum computed for $T_{\mathrm{r}}=4.0 \mathrm{~K}$ and $\mathrm{N}\left(\mathrm{HC}_{4} \mathrm{~N}\right)=3.7 \times 10^{11} \mathrm{~cm}^{-2}$.

two isomers have a very different molecular structure relative to linear $\mathrm{HC}_{4} \mathrm{~N}$ (Cernicharo et al. 2004). Hence, they are probably not formed in the reaction between $\mathrm{CH}$ and $\mathrm{HC}_{3} \mathrm{~N}$, which is the main pathway to the linear isomer. Finally, we searched for the related radicals CCN (Kakimoto \& Kasuya 1982; Ohshima \& Endo 1995) and $\mathrm{C}_{4} \mathrm{~N}$ (McCarthy et al. 2003). However, due to their low permanent dipole moment (Pd. \& Chandra 2001; Fiser $\&$ Polák 2013), we obtained very conservative $3 \sigma$ upper limits to their abundances of $1.8 \times 10^{12} \mathrm{~cm}^{-2}$ and $4.0 \times 10^{13} \mathrm{~cm}^{-2}$, respectively.

The abundance ratio $\mathrm{HCCN} / \mathrm{HC}_{4} \mathrm{~N}$ derived in $\mathrm{TMC}-1$ is $1.2 \pm 0.3$, which is very different than that derived in the carbonstar envelope IRC +10216 ( 9; Cernicharo et al. 2004). In IRC +10216 , this abundance ratio is a factor of two larger than the $\mathrm{HC}_{2 n+1} \mathrm{~N} / \mathrm{HC}_{2 n+3} \mathrm{~N}$ decrement observed for cyanopolyynes (Cernicharo et al. 2004), while in TMC-1 the $\mathrm{HCCN} / \mathrm{HC}{ }_{4} \mathrm{~N}$ ratio is two to three times lower than that of the cyanopolyyne decrement. The different behavior in TMC-1 compared to
IRC +10216 is probably caused by differences in the abundances of the precursors of $\mathrm{HCCN}$ and $\mathrm{HC}_{4} \mathrm{~N}$ (see Sect. 3.4).

\section{3. $\mathrm{CH}_{3} \mathrm{CH}_{2} \mathrm{CN}$}

This molecule is typical of warm molecular clouds, where it produces a forest of lines arising from all its isotopologues and lowenergy vibrational excited states (Demyk et al. 2007; Daly et al. 2013). It was searched for in TMC-1 by Minh \& Irvine (1991) without success. More recently, Lee et al. (2021) used stacking techniques, providing an upper limit to its column density in TMC-1 of $4 \times 10^{11} \mathrm{~cm}^{-2}$. We searched for the lines of this molecule in our TMC-1 $Q$-band survey. Figure B. 2 shows the six lines with $K_{a}=0$ and 1 detected. All of them appear at 4-5 $\sigma$ levels. The $K_{a}=2$ lines are too weak to be detected with the sensitivity of our survey.

We computed a synthetic spectrum using the rotational temperature derived for $\mathrm{CH}_{2} \mathrm{CHCN}(4.5 \mathrm{~K}$; see Appendix C) and a column density of $N\left(\mathrm{CH}_{3} \mathrm{CH}_{2} \mathrm{CN}\right)=1.1 \times 10^{11} \mathrm{~cm}^{-2}$ (with an estimated error of $30 \%$ ). The match between the observations and the model is very reasonable. We derived abundance ratios $\mathrm{CH}_{2} \mathrm{CHCN} / \mathrm{CH}_{3} \mathrm{CH}_{2} \mathrm{CN}=65 \pm 20$ and $\mathrm{CH}_{2} \mathrm{CHCCH} / \mathrm{CH}_{3} \mathrm{CH}_{2} \mathrm{CCH}=120 \pm 40$. It is interesting to compare the abundance ratio between vinyl cyanide and ethyl cyanide in TMC-1 and that in Orion KL. In the latter source it is 0.06 (López et al. 2014), which is a factor of $\sim 1100$ smaller than in TMC-1. The spatial distribution of both molecules in Orion KL has been analyzed by Cernicharo et al. (2016). Both species arise in regions with temperatures of 100 and $350 \mathrm{~K}$. The huge difference in this abundance ratio tells us about the different chemical processes prevailing in cold and warm molecular clouds. While the chemistry is dominated by the contribution of the evaporating ices covering dust grains in objects such as Orion KL, reactions between radicals and neutrals in cold dark clouds play a key role in producing these molecules.

\subsection{Chemistry of detected molecules}

After the discovery of abundant propylene in TMC-1 (Marcelino et al. 2007), the detection of an even larger, partially saturated, and abundant hydrocarbon, such as vinyl acetylene, in the same cloud brings to light the existence of a rich organic chemistry in cold dark clouds, going beyond the long-known presence of unsaturated carbon chains. Moreover, just as the hydrocarbons $\mathrm{CH}_{3} \mathrm{CCH}$ and $\mathrm{CH}_{2} \mathrm{CCH}_{2}$ act as precursors of the various nitriles $\mathrm{C}_{4} \mathrm{H}_{3} \mathrm{~N}$ found in TMC-1 (Marcelino et al. 2021), $\mathrm{CH}_{2} \mathrm{CHCCH}$ emerges as a very likely candidate precursor of the large nitriles with molecular formula $\mathrm{C}_{5} \mathrm{H}_{3} \mathrm{~N}$ that have recently been claimed in TMC-1 (Lee et al. 2021).

To get insight into the formation mechanism of $\mathrm{CH}_{2} \mathrm{CHCCH}$ and the other molecules covered in this study, we ran a pseudotime-dependent gas-phase chemical model that adopts typical parameters of cold dark clouds (see, e.g., Agúndez \& Wakelam 2013). We used the chemical network RATE12 from the UMIST database (McElroy et al. 2013), augmented with reactions relevant for the molecules of interest in this work, which are discussed below.

Vinyl acetylene is formed in the model through the neutralneutral gas-phase reactions $\mathrm{C}_{2}+\mathrm{C}_{2} \mathrm{H}_{6}, \mathrm{CH}+\mathrm{C}_{3} \mathrm{H}_{4}$ (where $\mathrm{C}_{3} \mathrm{H}_{4}$ stands for the two isomers $\mathrm{CH}_{3} \mathrm{CCH}$ and $\mathrm{CH}_{2} \mathrm{CCH}_{2}$ ), and $\mathrm{C}_{2} \mathrm{H}+\mathrm{C}_{2} \mathrm{H}_{4}$. These reactions have been found to be rapid at low temperatures (Canosa et al. 2007; Daugey et al. 2005; Bowman et al. 2012), and branching ratios have been measured for some of them (Loison \& Bergeat 2009; 


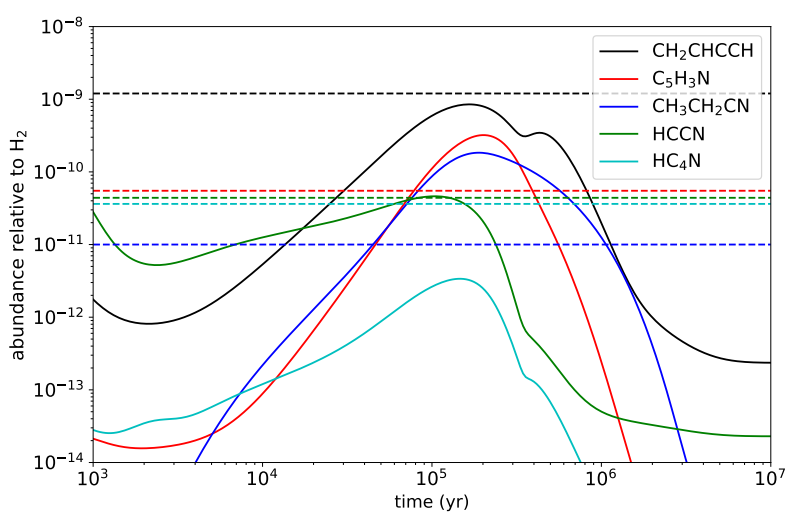

Fig. 5. Calculated fractional abundances of assorted molecules relevant to this study as a function of time. Horizontal dashed lines correspond to observed values.

Goulay et al. 2009; Bowman et al. 2012). Vinyl acetylene is predicted to form with a peak abundance of $\sim 10^{-9}$ relative to $\mathrm{H}_{2}$ (see Fig. 5), in good agreement with the value derived from observations. We also investigated whether cyanide derivatives of $\mathrm{CH}_{2} \mathrm{CHCCH}$ can be formed through the reaction $\mathrm{CN}+\mathrm{CH}_{2} \mathrm{CHCCH}$, which has been found to be rapid for temperatures down to $174 \mathrm{~K}$ (Yang et al. 1992). The peak abundance calculated for the generic species $\mathrm{C}_{5} \mathrm{H}_{3} \mathrm{~N}$, which accounts for different possible isomers, is a few times $10^{-10}$ relative to $\mathrm{H}_{2}$, somewhat above the observed abundance, which means that the reaction between $\mathrm{CN}$ and vinyl acetylene is a viable route to the $\mathrm{C}_{5} \mathrm{H}_{3} \mathrm{~N}$ isomers found in TMC-1 (Lee et al. 2021). Information on the kinetics of this reaction down to very low temperatures would be highly valuable to validate this mechanism.

Ethyl cyanide can also be formed efficiently in the gas phase in cold dark cloud conditions. In our chemical model the main route involves the radiative association between $\mathrm{CH}_{3}^{+}$ and $\mathrm{CH}_{3} \mathrm{CN}$ and the dissociative recombination of the ion $\mathrm{C}_{2} \mathrm{H}_{5} \mathrm{CNH}^{+}$with electrons, both of which have measured rate constants (Anicich 1993; Vigren et al. 2010). The calculated peak abundance is $\sim 10^{-10}$ relative to $\mathrm{H}_{2}$ (see Fig. 5), which is around ten times higher than the observed value. The chemical network probably misses some important reactions of destruction of $\mathrm{CH}_{3} \mathrm{CH}_{2} \mathrm{CN}$ (e.g., with neutral atoms or ions) which could explain the abundance overestimation.

We finally discuss the formation of the allenic molecules $\mathrm{HCCN}$ and $\mathrm{HC}_{4} \mathrm{~N}$ in TMC-1. The chemical network that involves HCCN is mostly taken from Loison et al. (2015), while that for $\mathrm{HC}_{4} \mathrm{~N}$ is assumed to be similar. The chemical model predicts HCCN to be around ten times more abundant than $\mathrm{HC}_{4} \mathrm{~N}$ (see Fig. 5), in contrast with observations that find both molecules to have similar abundances. The reason for this is that the main routes to $\mathrm{HCCN}$ and $\mathrm{HC}_{4} \mathrm{~N}$ are the reactions $\mathrm{CH}+\mathrm{HCN} / \mathrm{HNC}$ and $\mathrm{CH}+\mathrm{HC}_{3} \mathrm{~N}$, respectively (with rate constants based on Zabarnick et al. 1991), and the chemical model predicts that $\mathrm{HCN}$ and $\mathrm{HNC}$ together are around ten times more abundant than $\mathrm{HC}_{3} \mathrm{~N}$. However, observations indicate that $\mathrm{HC}_{3} \mathrm{~N}$ is as abundant as $\mathrm{HCN}$ and $\mathrm{HNC}$ in TMC-1 (e.g., Agúndez \& Wakelam 2013), and therefore if the reactions $\mathrm{CH}+\mathrm{HCN} / \mathrm{HNC}$ and $\mathrm{CH}+\mathrm{HC}_{3} \mathrm{~N}$ are the main pathways to $\mathrm{HCCN}$ and $\mathrm{HC}_{4} \mathrm{~N}$, respectively, one would expect similar abundances for $\mathrm{HCCN}$ and $\mathrm{HC}_{4} \mathrm{~N}$, in agreement with observations. The higher $\mathrm{HCCN} / \mathrm{HC}_{4} \mathrm{~N}$ observed in IRC +10216 is probably explained by the higher abundance of $\mathrm{HCN}$ compared to $\mathrm{HC}_{3} \mathrm{~N}$ in this source.
Acknowledgements. We thank Ministerio de Ciencia e Innovación of Spain (MICIU) for funding support through projects AYA2016-75066-C2-1-P, PID 2019-106110GB-I00, PID2019-107115GB-C21/AEI/10.13039/501100011033, and PID2019-106235GB-I00. We also thank ERC for funding through grant ERC-2013-Syg-610256-NANOCOSMOS. M.A. thanks MICIU for grant RyC2014-16277.

\section{References}

Agúndez, M., \& Wakelam, V. 2013, Chem. Rev., 113, 8710 Allen, M. D., Evenson, K. M., \& Brown, J. M. 2001, J. Mol. Spectr., 209, 143 Anicich, V. G. 1993, J. Phys. Chem. Ref. Data, 22, 1469 Bestmann, G., \& Dreizler, H. 1985, Z. Naturforsch., 40a, 263 Bowman, J., Goulay, F., Leone, S. R., \& Wilson, K. R. 2012, J. Phys. Chem. A, 116, 3907 Cabezas, C., Endo, Y., Roueff, E., et al. 2021, A\&A, 646, L1 Canosa, A., Páramo, A., Le Picard, S. D., \& Sims, I. R. 2007, Icarus, 187, 558 Cernicharo, J. 1985, Internal IRAM Report (Granada: IRAM) Cernicharo, J. 2012, EAS Publ. Ser., 58, 251

Cernicharo, J., \& Guélin, M. 1987, A\&A, 176, 299

Cernicharo, J., Heras, A. M., Tielens, A. G. G. M., et al. 2001, ApJ, 546, L123 Cernicharo, J., Guélin, M., \& Pardo, J. R. 2004, ApJ, 615, L145

Cernicharo, J., Kisiel, Z., Tercero, B., et al. 2016, A\&A, 587, L4 Cernicharo, J., Marcelino, N., Agúndez, M., et al. 2020a, A\&A, 642, L17 Cernicharo, J., Marcelino, N., Pardo, J. R., et al. 2020b, A\&A, 641, L9 Cernicharo, J., Marcelino, N., Agúndez, M., et al. 2020c, A\&A, 642, L8 Cernicharo, J., Cabezas, C., Endo, Y., et al. 2021a, A\&A, 646, L3 Cernicharo, J., Cabezas, C., Bailleux, S., et al. 2021b, A\&A, 646, L7 Daly, A. M., Bermúdez, C., López, A., et al. 2013, ApJ, 768, 81 Daugey, N., Caubet, P., Retail, B., et al. 2005, Phys. Chem. Chem. Phys., 7, 2921 Demaison, J., Boucher, D., Burie, J., \& Dubrulle, A. 1983, Z. Naturforsch., 38, 447

Demyk, K., Mäder, H., Tercero, B., et al. 2007, A\&A, 466, 255

Endo, Y., \& Ohshima, Y. 1993, J. Chem. Phys., 98, 6618

Fiser, J., \& Polák, R. 2013, Chem. Phys., 425, 126

Fossé, D., Cernicharo, J., Gerin, M., \& Cox, P. 2001, ApJ, 552, 168

Goulay, F., Trevitt, A. J., Meloni, G., et al. 2009, J. Am. Chem. Soc., 131, 993

Guélin, M., \& Cernicharo, J. 1991, A\&A, 244, L21

Ikuta, S., Tsuboi, T., \& Aoki, K. 2000, J. Mol. Struct., 528, 297

Inostroza, N., Huang, X., \& Lee, T. J. 2012, J. Chem. Phys., 135, 244310

Kaifu, N., Ohishi, M., Kawaguchi, K., et al. 2004, PASJ, 56, 69

Kakimoto, M., \& Kasuya, T. 1982, J. Mol. Spectr., 94, 380

Landsberg, B. M., \& Suenram, R. D. 1983, J. Mol. Spectr., 98, 210

Lee, K. L. K., Loomis, R. A., Burkhardt, A. M., et al. 2021, ApJ, 908, L11

Loison, J.-C., \& Bergeat, A. 2009, Phys. Chem. Chem. Phys., 11, 655

Loison, J.-C., Hébrard, E., Dobrijevic, M., et al. 2015, Icarus, 247, 218

López, A., Tercero, B., Kisiel, Z., et al. 2014, A\&A, 572, A44

Marcelino, N., Cernicharo, J., Agúndez, M., et al. 2007, ApJ, 665, L127

Marcelino, N., Agúndez, M., Tercero, B., et al. 2020, A\&A, 643, L6

Marcelino, N., Tercero, B., Agúndez, M., \& Cernicharo, J. 2021, A\&A, 646, L9

McCarthy, M. C., Gottlieb, C. A., Cooksy, A. L., \& Thaddeus, P. 1995, J. Chem. Phys., 103, 7779

McCarthy, M. C., Apponi, A. J., Gordon, V. D., et al. 1999a, J. Chem. Phys., 111,6750

McCarthy, M. C., Grabow, J.-U., Travers, M. J., et al. 1999b, ApJ, 513, 305

McCarthy, M. C., Fuchs, G. W., Kucera, J., et al. 2003, J. Chem. Phys., 118, 3549

McElroy, D., Walsh, C., Markwick, A. J., et al. 2013, A\&A, 550, A36

McGonagle, D., \& Irivine, W. M. 1996, A\&A, 310, 970

McGuire, B. A., Burkhardt, M., Kalenskii, S., et al. 2018, Science, 359, 202

Minh, Y. C., \& Irvine, W. M. 1991, Astrophys. Space Sci., 175, 165

Müller, H. S. P., Schlöder, F., Stutzki, J., et al. 2005, J. Mol. Struct., 742, 215

Ohshima, Y., \& Endo, Y. 1995, J. Mol. Spectr., 172, 225

Pardo, J. R., Cernicharo, J., \& Serabyn, E. 2001, IEEE Trans. Antennas Propag., 49, 12

Pickett, H. M., Poynter, R. L., Cohen, E. A., et al. 1998, J. Quant. Spectr. Rad. Transf., 60, 883

Pd., R., \& Chandra, P. 2001, J. Chem. Phys., 114, 1589

Saito, S., Endo, Y., \& Hirota, E. 1984, J. Chem. Phys., 80, 1427

Sobolev, G. A., Shcherbakov, A. M., \& Akishin, P. A. 1962, Opt. Spectr., 12, 78 Steber, A. L., Harris, B. J., Neill, J. L., et al. 2012, J. Mol. Spectr., 280, 3 Tang, J., Sumiyoshi, Y., \& Endo, Y. 1999, Chem. Phys. Lett., 315, 69

Tercero, F., López-Pérez, J. A., Gallego, J. D., et al. 2021, A\&A, 645, A37 Thorwirth, S., \& Lichau, H. 2003, A\&A, 398, L11

Thorwirth, S., Müller, H. S. P., Lichau, H., et al. 2004, J. Mol. Struct., 695, 263

Vigren, E., Hamberg, M., Zhaunerchyk, V., et al. 2010, ApJ, 722, 847

Yang, D. L., Yu, T., Wang, N. S., \& Lin, M. C. 1992, Chem. Phys., 160, 317

Zabarnick, S., Fleming, J. W., \& Lin, M. C. 1991, Chem. Phys., 150, 109 


\section{Appendix A: Line parameters for $\mathrm{CH}_{2} \mathrm{CHCCH}$ and model fitting procedure}

Line parameters were derived for $\mathrm{CH}_{2} \mathrm{CHCCH}$ by fitting a Gaussian line profile to the observed lines. A velocity range of $\pm 20 \mathrm{~km} \mathrm{~s}^{-1}$ around each feature was considered for the fit after a polynomial baseline was removed. The derived line parameters are given in Table A.1.

For the other species we show the synthetic spectrum resulting from the best fit model to all the lines computed using the MADEX code (Cernicharo 2012). We assumed a homogeneous rotational temperature for all rotational levels, a source of uniform brightness with a radius of 40" (Fossé et al. 2001), and a full linewidth at half power intensity of $0.6 \mathrm{~km} \mathrm{~s}^{-1}$, which represents a good averaged value to the linewidth of all observed lines. A fit to the observed line profiles and intensities provide the rotational temperature and the column density for the observed species. The final parameters derived in this way should be very similar to those derived from a standard rotational diagram. However, this model fit allows us to compare the modeled line profiles with those of the observations, which is particularly interesting when the rotational transitions exhibit hyperfine structure, as is the case for $\mathrm{HCCN}, \mathrm{HC}_{4} \mathrm{~N}$, and, to a lesser extent, $\mathrm{CH}_{3} \mathrm{CH}_{2} \mathrm{CN}$.

Table A.1. Observed line parameters for $\mathrm{CH}_{2} \mathrm{CHCCH}, \mathrm{HCCN}, \mathrm{HC}_{4} \mathrm{~N}$, and $\mathrm{CH}_{3} \mathrm{CH}_{2} \mathrm{CN}$.

\begin{tabular}{|c|c|c|c|c|c|c|}
\hline Transition & $\begin{array}{c}v \\
(\mathrm{MHz})\end{array}$ & $\underset{\left(\mathrm{mk} \mathrm{km} \mathrm{s}{ }^{-1}\right)}{T_{\mathrm{A}}^{*} \mathrm{~d} v}$ & $\begin{array}{c}v_{\mathrm{LSR}} \\
\left(\mathrm{km} \mathrm{s}^{-1}\right)\end{array}$ & $\begin{array}{c}\Delta v \\
\left(\mathrm{~km} \mathrm{~s}^{-1}\right)\end{array}$ & $\begin{array}{c}T_{\mathrm{A}}^{*} \\
(\mathrm{mK})\end{array}$ & Notes \\
\hline \multicolumn{7}{|l|}{$\mathrm{CH}_{2} \mathrm{CHCCH}$} \\
\hline $4_{04}-3_{03}$ & $35463.2066 \pm 0.0003$ & $2.1 \pm 0.4$ & $5.84 \pm 0.04$ & $0.79 \pm 0.09$ & $2.5 \pm 0.3$ & \multirow{7}{*}{ A } \\
\hline $4_{14}-3_{13}$ & $36270.1555 \pm 0.0003$ & $3.2 \pm 0.5$ & $5.81 \pm 0.04$ & $0.87 \pm 0.09$ & $3.5 \pm 0.4$ & \\
\hline $4_{23}-3_{22}$ & $36298.8671 \pm 0.0003$ & & & & & \\
\hline $4_{22}-3_{21}$ & $36327.0963 \pm 0.0003$ & $1.1 \pm 0.4$ & $5.81 \pm 0.15$ & $1.22 \pm 0.30$ & $0.8 \pm 0.3$ & \\
\hline $4_{13}-3_{12}$ & $37123.6151 \pm 0.0003$ & $1.0 \pm 0.3$ & $5.75 \pm 0.04$ & $0.35 \pm 0.15$ & $2.7 \pm 0.4$ & \\
\hline $5_{15}-4_{14}$ & $44323.5327 \pm 0.0004$ & $1.8 \pm 0.3$ & $5.71 \pm 0.05$ & $0.59 \pm 0.11$ & $2.8 \pm 0.5$ & \\
\hline $5_{05}-4_{04}$ & $45316.5327 \pm 0.0003$ & $1.7 \pm 0.4$ & $5.87 \pm 0.06$ & $0.58 \pm 0.15$ & $2.7 \pm 0.6$ & \\
\hline $5_{24}-4_{23}$ & $45369.7261 \pm 0.0003$ & & & & $\leq 1.5$ & $\mathrm{~B}$ \\
\hline $5_{23}-4_{22}$ & $45426.1532 \pm 0.0003$ & & & & $\leq 1.5$ & $\mathrm{~B}$ \\
\hline $5_{14}-4_{13}$ & $46398.7422 \pm 0.0005$ & $2.0 \pm 0.5$ & $5.76 \pm 0.06$ & $0.66 \pm 0.15$ & $2 . \overline{8} \pm 0.6$ & \\
\hline \multicolumn{7}{|l|}{$\mathrm{CH}_{3} \mathrm{CH}_{2} \mathrm{CN}$} \\
\hline $4_{1,4}-3_{1,3} 4-3$ & $34823.953 \pm 0.001$ & $0.9 \pm 0.3$ & $5.61 \pm 0.13$ & $0.71 \pm 0.15$ & $1.2 \pm 0.3$ & \multirow[b]{5}{*}{ NR } \\
\hline $4_{1,4}-3_{1,3} 5-4$ & $34824.089 \pm 0.001$ & $1.1 \pm 0.3$ & $5.74 \pm 0.15$ & $0.80 \pm 0.15$ & $1.3 \pm 0.3$ & \\
\hline $4_{0,4}-30,3-2$ & $35722.143 \pm 0.001$ & $1.2 \pm 0.4$ & $5.83 \pm 0.12$ & $1.15 \pm 0.30$ & $1.0 \pm 0.3$ & \\
\hline $4_{0,4}-3,34-3$ & $35722.208 \pm 0.001$ & $1.8 \pm 0.4$ & $5.70 \pm 0.06$ & $0.66 \pm 0.12$ & $2.5 \pm 0.3$ & \\
\hline $4_{0,4}-3_{0,3} 5-4$ & $35722.238 \pm 0.001$ & & & & & \\
\hline $4_{1,3}-3_{1,2} 5-4$ & $36739.711 \pm 0.001$ & $1.3 \pm 0.4$ & $5.56 \pm 0.08$ & $0.83 \pm 0.16$ & $1.5 \pm 0.3$ & BBR \\
\hline $5_{1,5}-4_{1,4} 6-5$ & $43516.229 \pm 0.001$ & $1.8 \pm 0.4$ & $6.00 \pm 0.09$ & $0.89 \pm 0.20$ & $1.9 \pm 0.4$ & NR \\
\hline $5_{1,5}-4_{1,4} 5-4$ & $43516.153 \pm 0.001$ & & & & & NR \\
\hline $5_{1,5}-4_{1,4} 4-3$ & $43516.186 \pm 0.001$ & & & & & NR \\
\hline $5_{0,5}-4_{0,4} 6-5$ & $44597.010 \pm 0.001$ & $2.3 \pm 0.4$ & $5.79 \pm 0.09$ & $1.09 \pm 0.18$ & $1.9 \pm 0.5$ & NR \\
\hline $5_{0,5}-4_{0,4} 4-3$ & $44596.954 \pm 0.001$ & & & & & NR \\
\hline $5_{0,5}-4_{0,4} 5-4$ & $44596.986 \pm 0.001$ & & & & & NR \\
\hline $5_{1,4}-4_{1,3} 6-5$ & $45908.544 \pm 0.001$ & $1.4 \pm 0.4$ & $6.09 \pm 0.06$ & $0.49 \pm 0.14$ & $2.5 \pm 0.6$ & NR \\
\hline $5_{1,4}-4_{1,3} 5-4$ & $45909.472 \pm 0.001$ & & & & & NR \\
\hline $5_{1,4}-4_{1,3} 4-3$ & $45908.514 \pm 0.001$ & & & & & NR \\
\hline \multicolumn{7}{|l|}{$\mathrm{HCCN}$} \\
\hline $1_{0}-0_{1} 2-15 / 2-5 / 2$ & $33681.972 \pm 0.014$ & $0.8 \pm 0.3$ & $5.53 \pm 0.07$ & $0.49 \pm 0.12$ & $1.4 \pm 0.3$ & \multirow{10}{*}{ NR } \\
\hline $1_{1}-0_{1} 1-13 / 2-3 / 2$ & $33711.125 \pm 0.009$ & $0.6 \pm 0.3$ & $5.74 \pm 0.10$ & $0.60 \pm 0.15$ & $0.9 \pm 0.3$ & \\
\hline $2{ }_{3}-1_{2} 3-35 / 2-5 / 2$ & $43599.379 \pm 0.004$ & $0.9 \pm 0.3$ & $5.75 \pm 0.12$ & $0.70 \pm 0.25$ & $1.2 \pm 0.3$ & \\
\hline $22_{3}-1_{2} 2-23 / 2-3 / 2$ & $43609.127 \pm 0.003$ & $1.1 \pm 0.4$ & $5.65 \pm 0.13$ & $0.96 \pm 0.40$ & $1.0 \pm 0.4$ & \\
\hline $2{ }_{3}-1_{2} 2-13 / 2-1 / 2$ & $43622.442 \pm 0.002$ & $1.2 \pm 0.3$ & $5.60 \pm 0.07$ & $0.62 \pm 0.12$ & $1.9 \pm 0.4$ & \\
\hline $2_{3}-1_{2} 2-15 / 2-3 / 2$ & $43613.513 \pm 0.002$ & & & & & \\
\hline $22_{3}-1_{2} 4-37 / 2-5 / 2$ & $43613.571 \pm 0.002$ & $5.0 \pm 0.5$ & $5.86 \pm 0.02$ & $0.77 \pm 0.04$ & $6.2 \pm 0.4$ & \\
\hline $2{ }_{3}-1_{2} 3-25 / 2-3 / 2$ & $43624.295 \pm 0.002$ & $2.8 \pm 0.4$ & $5.72 \pm 0.04$ & $0.70 \pm 0.08$ & $3.7 \pm 0.4$ & \\
\hline $2{ }_{3}-1_{2} 4-39 / 2-7 / 2$ & $43624.662 \pm 0.003$ & $2.7 \pm 0.4$ & $5.74 \pm 0.02$ & $0.53 \pm 0.06$ & $4.7 \pm 0.4$ & \\
\hline $22_{3}-1_{2} 3-27 / 2-5 / 2$ & $43624.800 \pm 0.002$ & $1.6 \pm 0.3$ & $5.73 \pm 0.03$ & $0.40 \pm 0.05$ & $3.8 \pm 0.4$ & \\
\hline
\end{tabular}

Notes. ${ }^{(A)}$ Blended with a strong feature. ${ }^{(B)}$ Three sigma upper limit. ${ }^{(N R)}$ Hyperfine structure line blended with other components of the same rotational transition. The line has been included in the fit to the previous or next entry in the table. 
Table A.1. continued.

\begin{tabular}{|c|c|c|c|c|c|c|}
\hline Transition & $\begin{array}{c}v \\
(\mathrm{MHz})\end{array}$ & $\underset{\left(\mathrm{mk} \mathrm{km} \mathrm{s}{ }^{-1}\right)}{T_{\mathrm{A}}^{*} \mathrm{~d} v}$ & $\begin{array}{c}v_{\mathrm{LSR}} \\
\left(\mathrm{km} \mathrm{s}^{-1}\right)\end{array}$ & $\begin{array}{c}\Delta v \\
\left(\mathrm{~km} \mathrm{~s}^{-1}\right)\end{array}$ & $\begin{array}{c}T_{\mathrm{A}}^{*} \\
(\mathrm{mK})\end{array}$ & Notes \\
\hline $2{ }_{2}-1_{1} 2-13 / 2-1 / 2$ & $43936.844 \pm 0.009$ & & & & $\leq 1.2$ & $\mathrm{~B}$ \\
\hline $22_{2}-1_{1} 1-11 / 2-1 / 2$ & $43939.743 \pm 0.007$ & & & & $\leq 1.2$ & $\mathrm{~B}$ \\
\hline $22_{2}-1_{1} 3-25 / 2-3 / 2$ & $43940.214 \pm 0.006$ & $2.2 \pm 0.5$ & $5.65 \pm 0.09$ & $1.05 \pm 0.25$ & $1.9 \pm 0.4$ & \\
\hline $2_{2}-1_{1} 2-23 / 2-3 / 2$ & $43943.474 \pm 0.007$ & & & & $\leq 1.2$ & B \\
\hline $22_{2}-1_{1} 1-03 / 2-1 / 2$ & $43945.275 \pm 0.006$ & $1.2 \pm 0.4$ & $5.45 \pm 0.13$ & $0.96 \pm 0.30$ & $1.1 \pm 0.4$ & \\
\hline $22_{2}-1_{1} 2-15 / 2-3 / 2$ & $43945.594 \pm 0.003$ & $1.0 \pm 0.4$ & $5.80 \pm 0.11$ & $0.72 \pm 0.20$ & $1.3 \pm 0.4$ & \\
\hline $2{ }_{2}-1_{1} 3-27 / 2-5 / 2$ & $43948.624 \pm 0.004$ & $2.6 \pm 0.4$ & $5.80 \pm 0.03$ & $0.66 \pm 0.09$ & $3.7 \pm 0.4$ & \\
\hline \multicolumn{7}{|l|}{$\mathrm{HC}_{4} \mathrm{~N}$} \\
\hline $77-6_{6} 6-511 / 2-9 / 2$ & $32233.047 \pm 0.010$ & $0.5 \pm 0.3$ & $5.78 \pm 0.20$ & $0.62 \pm 0.15$ & $0.8 \pm 0.3$ & \\
\hline $77-667-613 / 2-11 / 2$ & $32233.149 \pm 0.010$ & $1.5 \pm 0.4$ & $5.75 \pm 0.10$ & $0.98 \pm 0.05$ & $1.4 \pm 0.3$ & \\
\hline $7_{7}-6_{6} 8-7 \quad 15 / 2-13 / 2$ & $32233.290 \pm 0.003$ & $1.0 \pm 0.3$ & $5.80 \pm 0.14$ & $0.95 \pm 0.09$ & $1.0 \pm 0.3$ & \\
\hline $7_{7}-6_{6} 6-513 / 2-11 / 2$ & $32233.472 \pm 0.010$ & $1.6 \pm 0.5$ & $5.89 \pm 0.08$ & $1.04 \pm 0.10$ & $1.4 \pm 0.3$ & \\
\hline $7_{7}-6_{6} 7-615 / 2-13 / 2$ & $32233.545 \pm 0.003$ & & & & & \multirow[t]{3}{*}{ NR } \\
\hline $7_{7}-6_{6} 8-7 \quad 17 / 2-15 / 2$ & $32233.694 \pm 0.003$ & $0.9 \pm 0.3$ & $5.83 \pm 0.09$ & $0.74 \pm 0.18$ & $1.2 \pm 0.3$ & \\
\hline $78-677-615 / 2-13 / 2$ & $32365.728 \pm 0.010$ & $0.9 \pm 0.4$ & $5.93 \pm 0.11$ & $0.84 \pm$ & $0.9 \pm 0.3$ & \\
\hline $7_{8}-6_{7} 8-7 \quad 17 / 2-15 / 2$ & $32365.938 \pm 0.003$ & & & & & \multirow[t]{2}{*}{$\mathrm{NR}, \mathrm{BN}$} \\
\hline $78-677-613 / 2-11 / 2$ & $32365.972 \pm 0.003$ & $2.7 \pm 0.5$ & $5.83 \pm 0.04$ & $0.87 \pm 0.07$ & $2.9 \pm 0.3$ & \\
\hline $7_{8}-6_{7} 9-819 / 2-17 / 2$ & $32365.994 \pm 0.003$ & & & & & \multirow[t]{2}{*}{ NR,BN } \\
\hline $7_{8}-6_{7} 8-715 / 2-13 / 2$ & $32366.230 \pm 0.010$ & $1.9 \pm 0.4$ & $5.51 \pm 0.06$ & $0.95 \pm 0.13$ & $1.9 \pm 0.3$ & \\
\hline $7_{8}-6_{7} 9-8 \quad 17 / 2-15 / 2$ & $32366.230 \pm 0.010$ & & & & & \multirow[t]{5}{*}{ NR,BN } \\
\hline $87-767-613 / 2-11 / 2$ & $36665.590 \pm 0.004$ & $1.1 \pm 0.3$ & $5.98 \pm 0.15$ & $1.00 \pm$ & $1.1 \pm 0.3$ & \\
\hline $8_{7}-7_{6} 8-7 \quad 15 / 2-13 / 2$ & $36665.694 \pm 0.004$ & $0.8 \pm 0.3$ & $5.74 \pm 0.10$ & $0.57 \pm 0.17$ & $1.3 \pm 0.3$ & \\
\hline $8_{7}-7_{6} 6-511 / 2-9 / 2$ & $36665.831 \pm 0.004$ & $0.7 \pm 0.3$ & $5.76 \pm 0.06$ & $0.32 \pm 0.30$ & $1.9 \pm 0.3$ & \\
\hline $8_{7}-7_{6} 7-615 / 2-13 / 2$ & $36666.427 \pm 0.004$ & $2.2 \pm 0.4$ & $5.64 \pm 0.06$ & $1.07 \pm 0.14$ & $2.0 \pm 0.3$ & \\
\hline $8_{7}-7_{6} 8-7 \quad 17 / 2-15 / 2$ & $36666.497 \pm 0.004$ & & & & & \multirow[t]{3}{*}{ NR } \\
\hline $8_{7}-7_{6} 6-513 / 2-11 / 2$ & $36666.641 \pm 0.004$ & $0.8 \pm 0.4$ & $5.42 \pm 0.09$ & $0.68 \pm 0.18$ & $1.1 \pm 0.3$ & \\
\hline $8_{8}-7_{7} 7-613 / 2-11 / 2$ & $36837.871 \pm 0.005$ & $2.5 \pm 0.6$ & $5.65 \pm 0.09$ & $1.48 \pm 0.25$ & $1.6=$ & \\
\hline $8_{8}-7_{7} 8-7 \quad 15 / 2-13 / 2$ & $36837.939 \pm 0.005$ & & & & & NR \\
\hline $8_{8}-7_{7} 9-8 \quad 17 / 2-15 / 2$ & $36838.043 \pm 0.005$ & & & & & NR \\
\hline $8_{8}-7_{7} 7-615 / 2-13 / 2$ & $36838.172 \pm 0.005$ & $1.3 \pm 0.4$ & $5.66 \pm 0.09$ & $0.90=$ & $1.4 \pm 0.3$ & \\
\hline $8_{8}-7_{7} 8-7 \quad 17 / 2-15 / 2$ & $36838.240 \pm 0.005$ & $1.3 \pm 0.4$ & $6.15 \pm 0.05$ & $0.71 \pm 0.11$ & $1.7 \pm 0.3$ & \\
\hline $8_{8}-7_{7} 9-8 \quad 19 / 2-17 / 2$ & $36838.350 \pm 0.005$ & & & & & NR \\
\hline $89-78 \quad 8-7 \quad 17 / 2-15 / 2$ & $36942.973 \pm 0.004$ & & & & $\leq 0.9$ & $\mathrm{~B}$ \\
\hline $89-78 \quad 8-7 \quad 15 / 2-13 / 2$ & $36943.144 \pm 0.004$ & $3.2 \pm 0.5$ & $5.66 \pm 0.03$ & $0.82 \pm 0.07$ & $3 . \overline{7} \pm 0.3$ & \\
\hline $89-78$ 9-8 $19 / 2-17 / 2$ & $36943.144 \pm 0.004$ & & & & & NR \\
\hline $89-78$ 10-9 21/2-19/2 & $36943.179 \pm 0.004$ & & & & & NR \\
\hline $8_{9}-7_{8} 9-8 \quad 17 / 2-15 / 2$ & $36943.330 \pm 0.004$ & $1.5 \pm 0.4$ & $5.67 \pm 0.04$ & $0.60 \pm 0.08$ & $2.4 \pm 0.3$ & \\
\hline $89-7810-919 / 2-17 / 2$ & $36943.352 \pm 0.004$ & & & & & NR \\
\hline $9_{8}-8_{7} 8-7 \quad 15 / 2-13 / 2$ & $41309.798 \pm 0.007$ & $1.3 \pm 0.3$ & $5.94 \pm 0.15$ & $1.19 \pm 0.12$ & $1.0 \pm 0.3$ & \\
\hline $9_{8}-8_{7} 9-8 \quad 17 / 2-15 / 2$ & $41309.886 \pm 0.007$ & & & & & NR \\
\hline $98-877-613 / 2-11 / 2$ & $41309.971 \pm 0.007$ & $2.4 \pm 0.5$ & $5.67 \pm 0.10$ & $0.33 \pm 0.04$ & $0.7 \pm 0.3$ & \\
\hline $9_{8}-8_{7} 8-7 \quad 17 / 2-15 / 2$ & $41310.387 \pm 0.007$ & & & & & NR \\
\hline $9_{8}-8_{7} 9-8 \quad 19 / 2-17 / 2$ & $41310.452 \pm 0.007$ & $1.3 \pm 0.4$ & $5.85 \pm 0.06$ & $0.64 \pm 0.09$ & $1.9 \pm 0.3$ & \\
\hline $98-877-615 / 2-13 / 2$ & $41310.540 \pm 0.007$ & & & & & NR \\
\hline $9_{9}-8_{8} 8-7 \quad 15 / 2-13 / 2$ & $41442.624 \pm 0.007$ & & & & & NR \\
\hline $9_{9}-8_{8} 9-8 \quad 17 / 2-15 / 2$ & $41442.703 \pm 0.007$ & & & & & NR \\
\hline $9_{9}-8_{8} 10-919 / 2-17 / 2$ & $41442.760 \pm 0.007$ & & & & & NR \\
\hline $9_{9}-8_{8} 8-7 \quad 17 / 2-15 / 2$ & $41442.839 \pm 0.007$ & $2.4 \pm 0.6$ & $5.54 \pm 0.30$ & $2.44 \pm 0.50$ & $0.9 \pm 0.3$ & \\
\hline $99-88$ 9-8 19/2-17/2 & $41442.917 \pm 0.007$ & & & & & NR \\
\hline $9_{9}-8_{8} \quad 10-921 / 2-19 / 2$ & $41443.002 \pm 0.007$ & & & & & NR \\
\hline $9_{10}-899-819 / 2-17 / 2$ & $41527.729 \pm 0.007$ & $1.0 \pm 0.3$ & $5.68 \pm 0.06$ & $0.51 \pm 0.12$ & 1.8 & \\
\hline $9_{10}-899-817 / 2-15 / 2$ & $41527.847 \pm 0.007$ & & & & & NR \\
\hline $9_{10}-8910-921 / 2-19 / 2$ & $41527.865 \pm 0.007$ & & & & & NR \\
\hline $9_{10}-8911-1023 / 2-21 / 2$ & $41527.887 \pm 0.007$ & $2.7 \pm 0.6$ & $5.90 \pm 0.04$ & $0.70 \pm 0.11$ & $3.6 \pm 0.4$ & \\
\hline $910-8910-919 / 2-17 / 2$ & $41527.994 \pm 0.007$ & $0.6 \pm 0.3$ & $6.86 \pm 0.12$ & $0.53 \pm 0.29$ & $1.0 \pm 0.4$ & \\
\hline $9_{10}-8911-1021 / 2-19 / 2$ & $41528.006 \pm 0.007$ & & & & & NR \\
\hline
\end{tabular}


Table A.1. continued.

\begin{tabular}{|c|c|c|c|c|c|c|}
\hline Transition & $\begin{array}{c}v \\
(\mathrm{MHz})\end{array}$ & $\underset{\left(\mathrm{mk} \mathrm{km} \mathrm{s}{ }^{-1}\right)}{T_{\mathrm{A}}^{*} \mathrm{~d} v}$ & $\begin{array}{c}v_{\mathrm{LSR}} \\
\left(\mathrm{km} \mathrm{s}^{-1}\right)\end{array}$ & $\begin{array}{c}\Delta v \\
\left(\mathrm{~km} \mathrm{~s}^{-1}\right)\end{array}$ & $\begin{array}{c}T_{\mathrm{A}}^{*} \\
(\mathrm{mK})\end{array}$ & Notes \\
\hline $10_{10}-9_{9} 9-817 / 2-15 / 2$ & $46047.335 \pm 0.010$ & & & & & NR \\
\hline $10_{10}-9_{9} 9-919 / 2-17 / 2$ & $46047.440 \pm 0.010$ & & & & & NR \\
\hline $10_{10}-9_{9} 11-1021 / 2-19 / 2$ & $46047.445 \pm 0.010$ & $2.5 \pm 0.4$ & $5.86 \pm 0.08$ & $0.84 \pm 0.17$ & $2.8 \pm 0.6$ & \\
\hline $10_{10}-9_{9} 10-819 / 2-17 / 2$ & $46047.469 \pm 0.010$ & & & & & NR \\
\hline $10_{10}-9910-921 / 2-19 / 2$ & $46047.573 \pm 0.010$ & & & & & NR \\
\hline $10_{10}-9_{9} 11-1023 / 2-21 / 2$ & $46047.641 \pm 0.010$ & $2.0 \pm 0.4$ & $6.01 \pm 0.06$ & $0.57 \pm 0.13$ & $3.2 \pm 0.6$ & \\
\hline $10_{11}-9_{10} 10-921 / 2-19 / 2$ & $46117.484 \pm 0.010$ & & & & & NR \\
\hline $10_{11}-9_{10} 10-919 / 2-17 / 2$ & $46117.567 \pm 0.010$ & & & & & NR \\
\hline $10_{11}-9_{10} 11-1023 / 2-21 / 2$ & $46117.594 \pm 0.010$ & $1.6 \pm 0.5$ & $5.74 \pm 0.06$ & $0.51 \pm 0.12$ & $3.3 \pm 0.6$ & \\
\hline $10_{11}-9_{10} 12-1125 / 2-23 / 2$ & $46117.608 \pm 0.010$ & & & & & NR \\
\hline $10_{11}-9_{10} 11-1021 / 2-19 / 2$ & $46117.685 \pm 0.010$ & $1.3 \pm 0.5$ & $5.70 \pm 0.11$ & $0.62 \pm 0.17$ & $2.0 \pm 0.6$ & \\
\hline $10_{11}-9_{10} 12-1123 / 2-21 / 2$ & $46117.692 \pm 0.010$ & & & & & NR \\
\hline $\mathrm{CH}_{2} \mathrm{CHCN}$ & & & & & & \\
\hline $4_{1,4}-3_{1,3} 4-4$ & $37017.816 \pm 0.001$ & $1.7 \pm 0.3$ & $5.87 \pm 0.05$ & $0.68 \pm 0.11$ & $2.4 \pm 0.4$ & \\
\hline $4_{1,4}-3_{1,3} 4-3$ & $37018.829 \pm 0.001$ & $26.8 \pm 0.8$ & $5.77 \pm 0.01$ & $0.69 \pm 0.02$ & $36.3 \pm 0.4$ & \\
\hline $4_{1,4}-3_{1,3} 3-2$ & $37018.926 \pm 0.001$ & $22.8 \pm 0.7$ & $5.73 \pm 0.02$ & $0.68 \pm 0.05$ & $31.4 \pm 0.4$ & \\
\hline $4_{1,4}-3_{1,3} 5-4$ & $37018.981 \pm 0.001$ & $29.3 \pm 0.8$ & $5.74 \pm 0.01$ & $0.64 \pm 0.02$ & $42.9 \pm 0.4$ & \\
\hline $4_{1,4}-3_{1,3} 3-3$ & $37020.293 \pm 0.001$ & $0.9 \pm 0.3$ & $5.72 \pm 0.15$ & $0.51 \pm 0.34$ & $1.6 \pm 0.4$ & \\
\hline $4_{0,4}-3_{0,3} 4-4$ & $37903.587 \pm 0.001$ & $3.0 \pm 0.4$ & $5.81 \pm 0.03$ & $0.66 \pm 0.08$ & $4.3 \pm 0.4$ & \\
\hline $4_{0,4}-3_{0,3} 3-2$ & $37904.770 \pm 0.001$ & $31.7 \pm 0.8$ & $5.87 \pm 0.01$ & $0.69 \pm 0.02$ & $42.8 \pm 0.4$ & \\
\hline $4_{0,4}-3_{0,3} 4-3$ & $37904.850 \pm 0.001$ & $87.2 \pm 1.5$ & $5.75 \pm 0.02$ & $0.72 \pm 0.01$ & $113.8 \pm 0.4$ & \\
\hline $4_{0,4}-3_{0,3} 5-4$ & $37904.880 \pm 0.001$ & & & & & NR \\
\hline $4_{0,4}-3_{0,3} 3-3$ & $37906.474 \pm 0.001$ & $1.5 \pm 0.4$ & $5.72 \pm 0.03$ & $0.49 \pm 0.12$ & $2.9 \pm 0.4$ & \\
\hline $4_{2,3}-3_{2,2} 4-3$ & $37939.248 \pm 0.001$ & $4.2 \pm 0.5$ & $5.90 \pm 0.01$ & $0.62 \pm 0.03$ & $6.3 \pm 0.4$ & \\
\hline $4_{2,3}-3_{2,2} 5-4$ & $37939.763 \pm 0.001$ & $6.2 \pm 0.5$ & $5.78 \pm 0.01$ & $0.74 \pm 0.04$ & $7.8 \pm 0.4$ & \\
\hline $4_{2,3}-3_{2,2} 3-2$ & $37939.896 \pm 0.001$ & $2.6 \pm 0.4$ & $5.79 \pm 0.02$ & $0.59 \pm 0.05$ & $4.1 \pm 0.4$ & \\
\hline $4_{2,2}-3_{2,1} 4-3$ & $37973.989 \pm 0.001$ & $4.7 \pm 0.4$ & $5.83 \pm 0.02$ & $0.74 \pm 0.04$ & $6.0 \pm 0.4$ & \\
\hline $4_{2,2}-3_{2,1} 5-4$ & $37974.504 \pm 0.001$ & $5.5 \pm 0.5$ & $5.80 \pm 0.01$ & $0.68 \pm 0.03$ & $7.6 \pm 0.4$ & \\
\hline $4_{2,2}-3_{2,1} 3-2$ & $37974.636 \pm 0.001$ & $3.1 \pm 0.4$ & $5.82 \pm 0.02$ & $0.65 \pm 0.05$ & $4.4 \pm 0.4$ & \\
\hline $4_{1,3}-3_{1,2} 4-4$ & $38846.762 \pm 0.001$ & $1.5 \pm 0.4$ & $5.88 \pm 0.06$ & $0.89 \pm 0.13$ & $1.6 \pm 0.4$ & \\
\hline $4_{1,3}-3_{1,2} 4-3$ & $38847.641 \pm 0.001$ & $27.4 \pm 0.8$ & $5.75 \pm 0.00$ & $0.66 \pm 0.01$ & $38.9 \pm 0.4$ & \\
\hline $4,3-3,23-2$ & $38847.747 \pm 0.001$ & $55.4 \pm 1.1$ & $5.88 \pm 0.00$ & $0.79 \pm 0.01$ & $66.3 \pm 0.4$ & \\
\hline $4_{1,3}-3_{1,2} 5-4$ & $38847.790 \pm 0.001$ & & & & & NR \\
\hline $4_{1,3}-3_{1,2} 3-3$ & $38848.933 \pm 0.001$ & $2.5 \pm 0.4$ & $5.81 \pm 0.02$ & $0.63 \pm 0.06$ & $3.4 \pm 0.6$ & \\
\hline $5_{1,5}-4_{1,4} 5-4$ & $46266.887 \pm 0.001$ & & & & & NR \\
\hline $5_{1,5}-4_{1,4} 4-3$ & $46266.926 \pm 0.001$ & $70.2 \pm 1.2$ & $5.76 \pm 0.01$ & $0.87 \pm 0.01$ & $76.0 \pm 0.6$ & \\
\hline $5,5-4_{1,4} 6-5$ & $46266.971 \pm 0.001$ & & & & & NR \\
\hline $5_{0,5}^{1,4}-4_{0,4} 5-5$ & $47353.356 \pm 0.001$ & $1.9 \pm 0.4$ & $5.80 \pm 0.05$ & $0.56 \pm 0.11$ & $3.2 \pm 0.6$ & \\
\hline $5_{0,5}-4_{0,4} 4-3$ & $47354.605 \pm 0.001$ & & & & & NR \\
\hline $5_{0,5}-4_{0,4} 5-4$ & $47354.648 \pm 0.001$ & $104.0 \pm 1.5$ & $5.80 \pm 0.01$ & $0.74 \pm 0.01$ & $132.9 \pm 0.6$ & \\
\hline $5_{0,5}-4_{0,4} 6-5$ & $47354.670 \pm 0.001$ & & & & & NR \\
\hline $5_{0,5}-4_{0,4} 4-4$ & $47356.230 \pm 0.001$ & $2.5 \pm 0.4$ & $6.00 \pm 0.06$ & $0.75 \pm 0.09$ & $3.1 \pm 0.6$ & \\
\hline $5_{2,4}-4_{2,3} 5-4$ & $47419.606 \pm 0.001$ & $5.5 \pm 0.6$ & $5.77 \pm 0.02$ & $0.69 \pm 0.05$ & $7.6 \pm 0.6$ & \\
\hline $5_{2,4}-4_{2,3} 6-5$ & $47419.876 \pm 0.001$ & $8.6 \pm 0.8$ & $5.75 \pm 0.02$ & $0.70 \pm 0.05$ & $11.5 \pm 0.6$ & \\
\hline $5,4-4,34-3$ & $47419.904 \pm 0.001$ & & & & & NR \\
\hline $5,4-4,35-4$ & $48552.516 \pm 0.001$ & & & & & NR \\
\hline $5_{1,4}-4_{1,3} 4-3$ & $48552.559 \pm 0.001$ & $73.8 \pm 1.9$ & $5.77 \pm 0.01$ & $0.86 \pm 0.02$ & $80.3 \pm 0.9$ & \\
\hline $5_{1,4}-4{ }_{1,3} 6-5$ & $48552.598 \pm 0.001$ & & & & & NR \\
\hline
\end{tabular}




\section{Appendix B: Ethyl acetylene and ethyl cyanide}
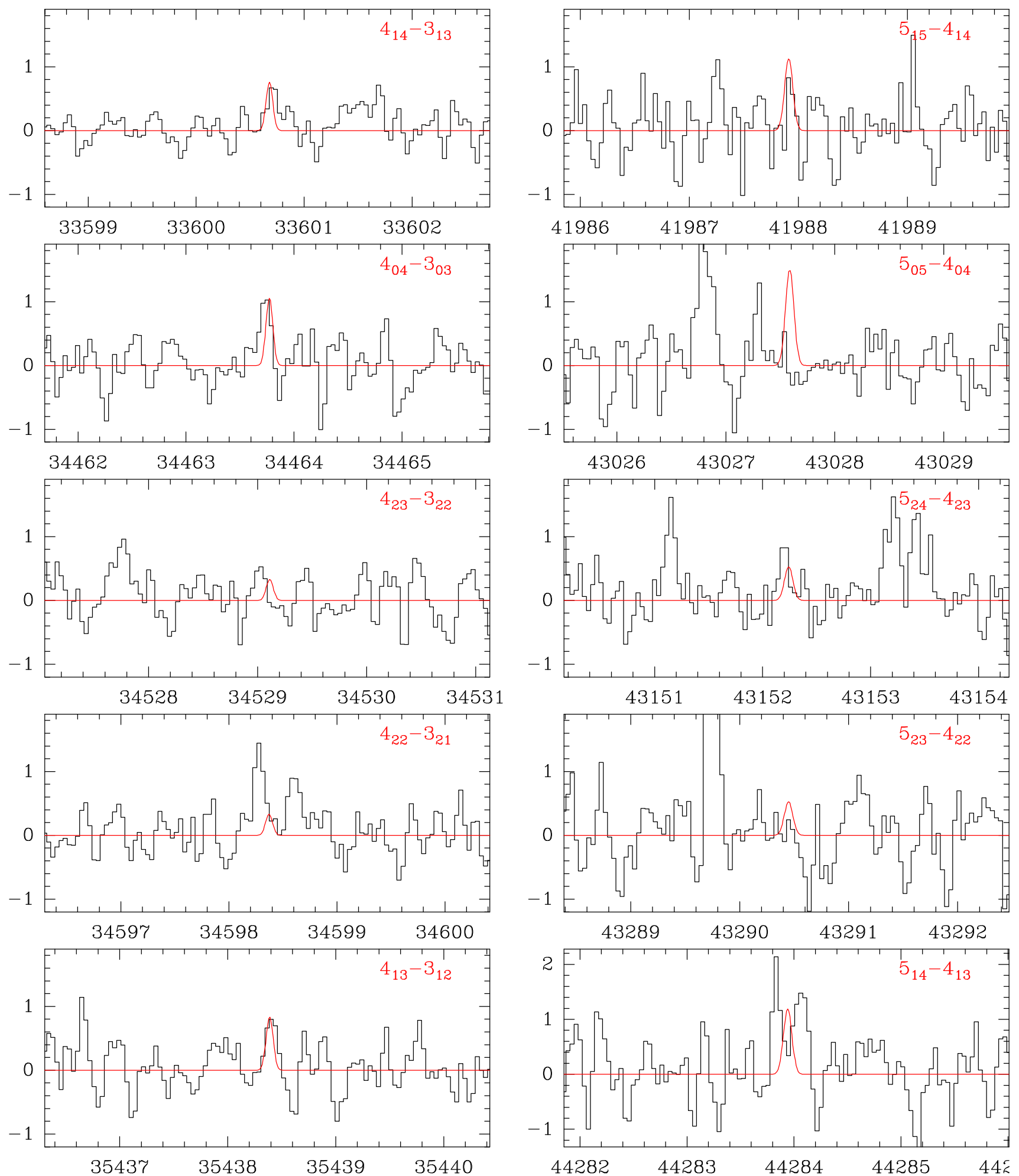

Fig. B.1. Observed lines of $\mathrm{CH}_{3} \mathrm{CH}_{2} \mathrm{CCH}$ in the $Q$-band toward TMC-1. The abscissa corresponds to the rest frequency assuming a local standard of rest velocity of $5.83 \mathrm{~km} \mathrm{~s}^{-1}$. The ordinate is the antenna temperature, corrected for atmospheric and telescope losses, in mK. The red line shows the synthetic spectrum obtained using the parameters derived from a rotational diagram of the observed lines $\left(T_{\mathrm{r}}=5 \mathrm{~K}\right.$ and $\left.\mathrm{N}\left(\mathrm{CH}_{3} \mathrm{CH}_{2} \mathrm{CCH}\right)=9.0 \times 10^{11} \mathrm{~cm}^{-2}\right)$. The rotational quantum numbers are provided in the upper right corners of each panel. 
We searched for the lines of ethyl acetylene, $\mathrm{CH}_{3} \mathrm{CH}_{2} \mathrm{CCH}$, a molecule for which accurate laboratory data are available up to 317.7 GHz (Demaison et al. 1983; Landsberg \& Suenram 1983; Bestmann \& Dreizler 1985; Steber et al. 2012) and which has moderate dipole moments of $\mu_{a}=0.763 \mathrm{D}$ and $\mu_{b}=0.17 \mathrm{D}$ (Landsberg \& Suenram 1983). The barrier to internal rotation is very high (Bestmann \& Dreizler 1985), and therefore the ground state does not show significant splitting between the $A$ and $E$ species. Of the ten lines expected for this molecule in the $Q$-band, five are detected at a $3 \sigma$ level, two are blended with other weak features slightly shifted in frequency, and three are too weak. Using stacking techniques (see below) and removing the blended lines, which could introduce a significant bias in the final spectrum, we detected a signal at $5 \sigma$ at the correct velocity, as shown in Fig. 2. However, we have no explanation for the lack of emission at the frequency of the $5_{05}-4_{04}$ transition other than that the data are too noisy at its frequency (see Fig. B.1). It is expected to be the strongest feature for the parameters we used for the synthetic spectrum $\left(T_{\mathrm{r}}=5 \mathrm{~K}\right.$, $\left.\mathrm{N}\left(\mathrm{CH}_{3} \mathrm{CH}_{2} \mathrm{CCH}\right)=9 \times 10^{11} \mathrm{~cm}^{-2}\right)$.

For $\mathrm{CH}_{3} \mathrm{CH}_{2} \mathrm{CCH}$, all the expected strongest lines in the $Q$-band are shown in Fig. B.1, and Fig. 2 shows the resulting stacked profile. The stacking procedure we used is rather simple: a velocity range of $\pm 20 \mathrm{~km} \mathrm{~s}^{-1}$ was selected for each line and the noise, $\sigma$, outside $5.83 \pm 0.5 \mathrm{~km} \mathrm{~s}^{-1}$ was computed (with known and unknown lines in each individual spectrum blanked). The data were normalized to the expected intensity of each transition computed under local thermodynamic equilibrium for a rotational temperature of $5 \mathrm{~K}$, the same as the value derived for $\mathrm{CH}_{2} \mathrm{CHCCH}$. Finally, all the data were multiplied by the expected intensity of the strongest transition in the sample. The lines are optically thin, and hence the intensity of all lines scale in the same way with the assumed column density. Each individual spectrum was weighted as $1 / \sigma_{\mathrm{N}}^{2}$, where $\sigma_{\mathrm{N}}$ now contains the normalization intensity factor. All rotational transitions falling in the frequency ranges where our data have the highest sensitivity were detected (transitions $4_{14}-3_{13}, 4_{04}-3_{03}, 4_{13}-3_{12}$, $5_{15}-4_{14}$, and $\left.5_{24}-5_{23}\right)$. Two of the observed transitions are heavily blended $\left(4_{22}-3_{21}\right.$ and $\left.5_{14}-4_{13}\right)$ and were excluded from the stacked spectrum. Two $K_{a}=2$ transitions, which are expected to be weak, were not detected $\left(4_{23}-3_{22}\right.$ and $\left.5_{23}-4_{22}\right)$ but were included in the data stacking with the corresponding weights, as explained above. The data for the strongest rotational transition, the $5_{05}-4_{04}$, have a sensitivity of $0.6 \mathrm{mK}$. The expected intensity is $1.3 \mathrm{mK}$. This rotational transition was included in the stacked spectrum, although it is clearly not detected at the noise level of the data. Figure 2 shows the resulting spectrum from this procedure. A feature, at exactly the velocity of the cloud, appears at a $5 \sigma$ level $(\sigma=0.16 \mathrm{mK})$. Although a positive detection of ethyl acetylene is highly possible, we consider it as tentative. Longer integration times are needed to confirm the detection of this species.

In our survey we observed a large number of unidentified lines at the level of 1-5 mK (see Figs. 1, 3, 4, and B.1). Moreover, the isotopologues of abundant species contribute with several hundred lines. Consequently, stacking techniques that could compete in sensitivity with our survey may provide false positive or negative results for low abundant molecular species. An example is the case of $\mathrm{CH}_{3} \mathrm{CH}_{2} \mathrm{CN}$, which was detected in our work (see Sect. 3.3 and Fig. B.2), while only upper limits were obtained by Lee et al. (2021). The observed lines of $\mathrm{CH}_{3} \mathrm{CH}_{2} \mathrm{CN}$, together with the best model fit to the observed emission, are shown in Fig. B.2.

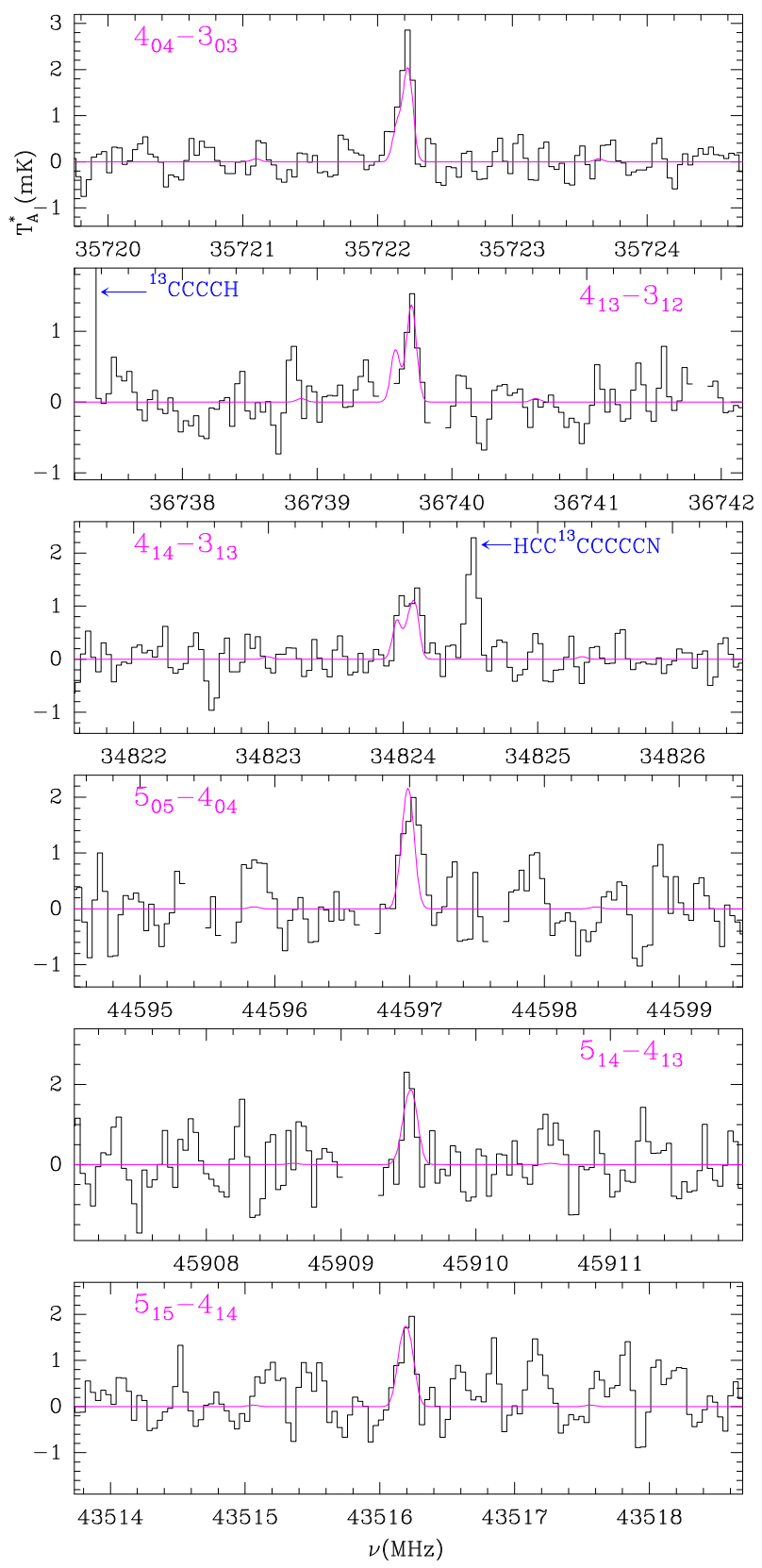

Fig. B.2. Observed lines of $\mathrm{CH}_{3} \mathrm{CH}_{2} \mathrm{CN}$ in the $31-50 \mathrm{GHz}$ frequency range toward TMC-1. The abscissa corresponds to the rest frequency assuming a local standard of rest velocity of $5.83 \mathrm{~km} \mathrm{~s}^{-1}$. The ordinate is the antenna temperature, corrected for atmospheric and telescope losses, in $\mathrm{mK}$. The violet line shows the synthetic spectrum computed for $T_{\mathrm{r}}=4.5 \mathrm{~K}$ and $\mathrm{N}\left(\mathrm{CH}_{3} \mathrm{CH}_{2} \mathrm{CN}\right)=1.1 \times 10^{11} \mathrm{~cm}^{-2}$. 


\section{Appendix C: Vinyl cyanide, $\mathrm{CH}_{2} \mathrm{CHCN}$}

Vinyl cyanide produces a very rich spectrum in the $31-50 \mathrm{GHz}$ range, with most of its lines exhibiting the hyperfine structure due to the nitrogen nucleus. All the observed lines are shown in Fig. C.1. The model fitting procedure provides a rotational temperature of $4.5 \pm 0.5 \mathrm{~K}$ and a column density of $(6.5 \pm 0.5) \times 10^{12} \mathrm{~cm}^{-2}$. Its abundance relative to vinyl acetylene and ethyl cyanide is discussed in Sects. 3.1, 3.3, and 3.4.
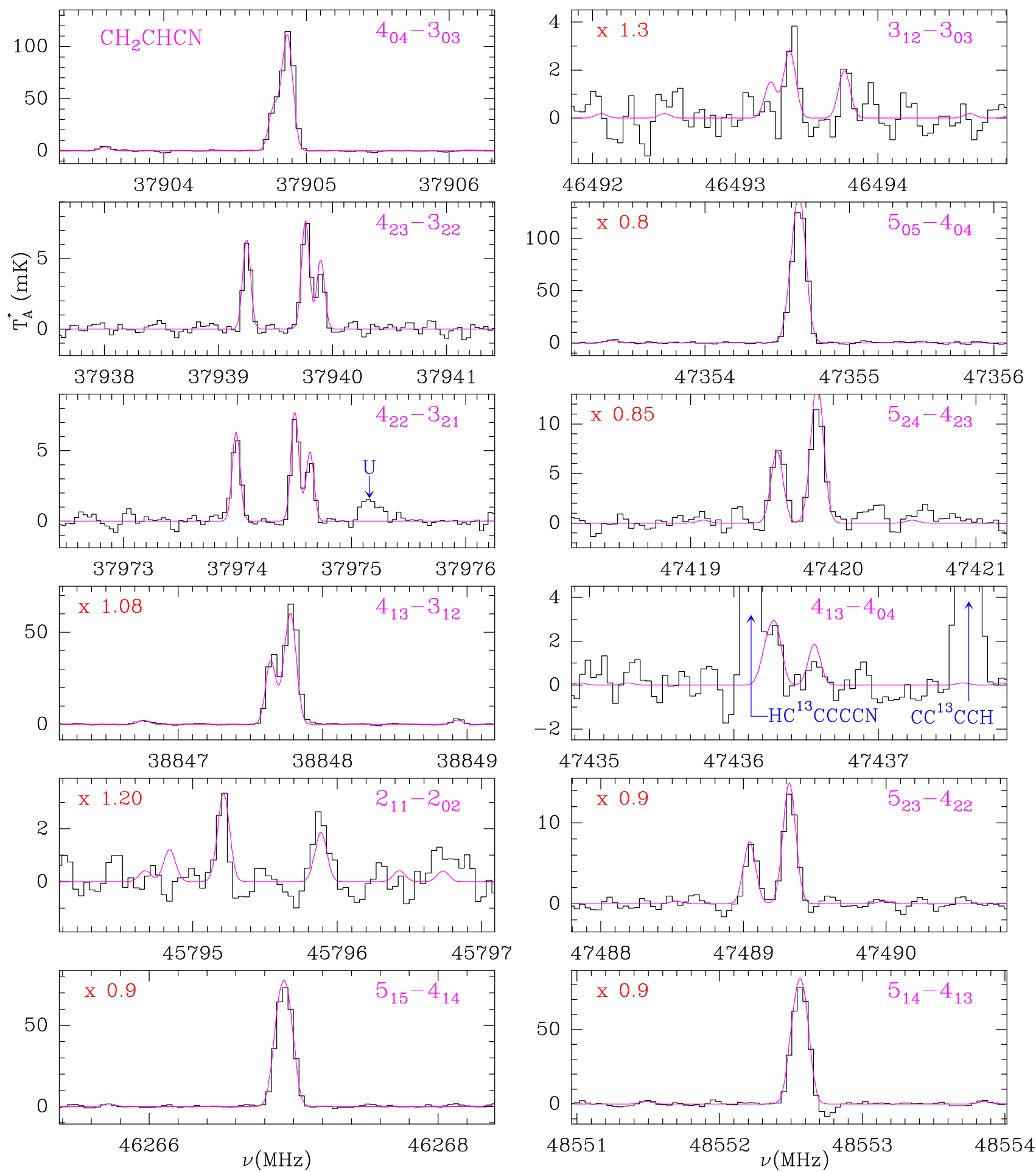

Fig. C.1. Observed lines of $\mathrm{CH}_{2} \mathrm{CHCN}$ in the $31-50 \mathrm{GHz}$ frequency range toward TMC-1. The abscissa corresponds to the rest frequency assuming a local standard of rest velocity of $5.83 \mathrm{~km} \mathrm{~s}^{-1}$. The ordinate is the antenna temperature, corrected for atmospheric and telescope losses, in mK. The violet line shows the synthetic spectrum obtained using the parameters derived from a rotational diagram of the observed lines $\left(T_{\mathrm{r}}=4.5 \pm 0.3 \mathrm{~K}\right.$ and $\left.\mathrm{N}\left(\mathrm{CH}_{2} \mathrm{CHCN}\right)=(6.5 \pm 0.5) \times 10^{12} \mathrm{~cm}^{-2}\right)$. Numbers in the upper left corners of the panels indicate the multiplicative factor applied to the synthetic spectrum to match the data. The rotational quantum numbers are provided in the upper right corners of each panel. The hyperfine structure of each rotational transition has been taken into account in the calculation of the synthetic spectra. Line parameters are given in Table A.1. 